\title{
Multiband Printed Loop Antenna for UWB Applications
}

\author{
${ }^{\text {*1 }}$ Shailendra Shastri, ${ }^{2}$ Ravish R. Singh, ${ }^{3}$ K.V. Ajetrao \\ ${ }^{1}$ Pacific Academy of Higher Education and Research University, Udaipur, India \\ ${ }^{2}$ Thakur Educational Trust, Mumbai, India \\ ${ }^{3}$ K.J. Somaiya College of Engineering, Mumbai, India \\ Email: shastri_shailendra@rediffmail.com,ravishrsingh@yahoo.com,kiran_ajetrao@rediffmail.com
}

Received: $9^{\text {th }}$ April 2018, Accepted: $14^{\text {th }}$ May 2018, Published: $30^{\text {th }}$ June 2018

\begin{abstract}
A printed loop antenna is designed to produce three distinct bands to cover six different frequency bands from UWB groups. Loop is fed using a printed BALUN transformer. The first band is available from $3.09 \mathrm{GHz}$ to $4.44 \mathrm{GHz}$, the second band is available from $6.11 \mathrm{GHz}$ to $7 \mathrm{GHz}$ and the third band is available from $8.85 \mathrm{GHz}$ to $10.5 \mathrm{GHz}$. The measured results are in good agreement with the simulated results. Frequency band from $3.0 \mathrm{GHz}$ to $4.44 \mathrm{GHz}$ covers UWB BAND-1 and BAND-2, the frequency band from $6.11 \mathrm{GHz}$ to $7 \mathrm{GHz}$ covers UWB BAND7 and the last band from $8.85 \mathrm{GHz}$ to $10.5 \mathrm{GHz}$ covers UWB BAND-12, BAND-13, and BAND-14. Antenna rejects IEEE $802.11 \mathrm{Wi}-\mathrm{Fi} / \mathrm{WLAN}$ band at $5.8 \mathrm{GHz}$.
\end{abstract}

Keywords: BALUN Transformer, Coplanar Stripline, Loop Antenna, Ultra Wideband, Wavelength.

\section{Introduction}

There is a continuous increase in the demand for more and more band with high data rate; therefore, UWB antennas have dragged attention of antenna researchers. Ultrawideband technology occupies a very large bandwidth and thus ensures the transmission of the larger data rate in the range of Gbps. In order to cover larger bands researchers have proposed different antennas to cover UWB frequency range from $3.1 \mathrm{GHz}$ to $10.6 \mathrm{GHz}$. An UWB antenna senses all the frequency falling in its band but in order to reject busy channel and receive only free channels, multiband UWB antennas are preferred. Multiband antennas are antennas which generates multiple bands of interest. There can be different approaches to generate multiple bands: a) it is well known that the resonant frequency depends on impedance which in turn depends on the distribution of current in the antenna. Therefore multiband antennas can be designed using current reconfiguration techniques. Antenna current can be reconfigured by using electronic or electromechanical switches. b) Every antenna resonates at the designed fundamental frequency and its multiple frequencies.

This approach can be used to design a multiband antenna and is simpler than the approach (a). There are several approaches available in the literature to generate multiple bands in the loop antenna. A 3-D loop antenna with three tuning strips produces five different bands for the application in smartphones. These bands are considered for $-6 \mathrm{~dB}$ reflections coefficient [1]. A similar loop antenna is proposed to cover GSM 850/900, DCS 1800, PCS 1900, UMTS 2100 and LTE $2300 / 2500$ bands by introducing reconfigurability technique. These bands are generated with the help of RF switch which is connected to reactive elements to influence the bands [2]. Dual asymmetric Loop antennas are integrated to work on WLAN/WiMAX. To have a larger impedance bandwidth a nonuniform loop width is used along with ground traces [3]. Loop antenna with outer SRR and inner strip can be operated as multi-mode and wideband antenna. Outer SRR loop radiates for odd modes and inner Loop radiates for even modes thus the multimode operation is achieved [4]. A loop antenna added with capacitive gaps and a passive strip along with a passive loop of smaller dimension than the main loop improves the gain and bandwidth of conventional loop antenna. By optimizing the gap between the main loop and passive strip and passive loop the upper cut-off frequency can be improved [5]. A small non-planar dual-meander folded loop antenna along with a disc loaded monopole produces omnidirectional radiation pattern with radiation efficiency of $65 \%$ and bandwidth of $10.8 \%$. Bandwidth is enhanced due to proximity coupling between meander loop and monopole [6].

All the antennas proposed in these literatures either have complicated 3-D shape of loop or array of the loop and other passive structures are used to generate multiple bands.

In this paper, we are proposing a simple and planar structure of loop antenna which covers six different bands from UWB frequency range listed in figure 1 . All the bands are generated without using any array or switch.

Entire work is divided into four sections, section 2 covers the design of loop for a reference impedance of $125 \Omega$ and development of folded CPS (coplanar strip line) line to feed balanced loop antenna. Section 3 covers interfacing of proposed antenna with BALUN transformer and finally section 4 covers the measurement of proposed antenna. 


\section{Antenna Configuration and Design}

Consideration

Figure 1 shows the distribution of frequency spectrum of UWB. Each band is of $528 \mathrm{MHz}$ wide, the centre frequency of each band is shown in the figure.

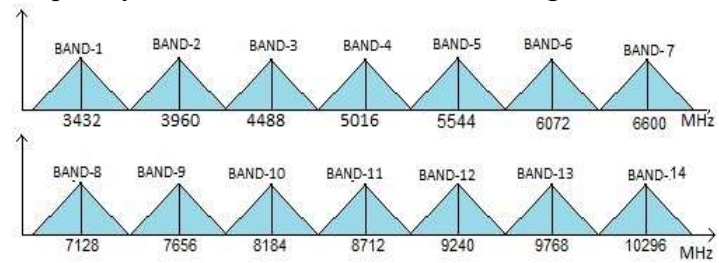

Figure 1: Band Group Allocation for UWB.

In order to cover UWB, printed circular loop is chosen. UWB ranges from $3.1 \mathrm{GHz}$ to $10.6 \mathrm{GHz}$, therefore, the dimension of the loop is chosen to cover this band. Theory suggests that a large loop antenna when operated at a wavelength near to the circumference of the loop, first resonance occurs at the chosen wavelength and other resonance occurs at multiple of this wavelength. Loop antenna with different wire radii offers different impedances [7]. Loop with circumference much lesser than wavelength typically $\lambda / 10$ is treated as the small loop and is not a good radiator [8].

Simulation is performed using IE3D simulation software. The final antenna is also simulated using CST STUDIO SUITE for comparison sake. Theory suggests that the electrical characteristic i.e. impedance of wire loop antenna is the function of the thickness of the wire. This relation between the thickness of wire $2 b$ and radius of the loop is referred as thickness factor $(\Omega)$.

$$
\Omega=2 \ln (2 \pi r / b)
$$

Where $\Omega$ is thickness factor, $r$ is the radius of the loop.

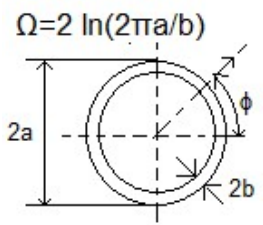

Figure 2: Loop Antenna showing the Relation between Wire Radius and Loop Radius.

Figure 2 shows the graphical significance of thickness factor. Loop antenna is also categorized as a thin and a thick loop. The thin antenna has $\Omega$ larger than 9 and resonates at more than one frequency. The thick antenna is capacitive in nature with the advantage of having almost uniform resistance. Since antenna impedance depends on the thickness factor of the loop by varying thickness of loop, antenna bandwidth can be varied easily.

The proposed antenna is a large loop as it is a good radiator. Least frequency of interest is $3 \mathrm{GHz}$ in order to cover UWB range of $3.1 \mathrm{GHz}$ to $10.6 \mathrm{GHz}$. The circumference of the loop is calculated using the following relation:

$$
C=2 \pi r=c / f
$$

Where $C$ is the circumference of the loop antenna in $\mathrm{m}, r$ is the radius of the loop in $\mathrm{m}, c$ is the speed of light in free space in $\mathrm{m} / \mathrm{s}, f$ is the least frequency of loop in $\mathrm{Hz}$.

Considering the fact that multiband antenna resonates at multiple frequencies, the thin loop antenna is chosen for the proposed design. For conversion from wire to the printed antenna, wire thickness is changed into the width of the printed antenna using relation given in [9]:

$$
b=\frac{w}{4}
$$

Where $w$ is the width of printed loop and $b$ is the radius of the wire, Figure 2.

In order to design printed loop, free space wavelength at $3 \mathrm{GHz}$ is calculated and is $100 \mathrm{~mm}$ so the radius of the loop is approximately $15.9 \mathrm{~mm}$, using relation (2). For the design of antenna Duroid 5880 with the dielectric constant of 2.2 and thickness of $0.787 \mathrm{~mm}$ is chosen. To find out the optimum radius of the printed loop on Duroid 5880 to cover the least frequency of 3 $\mathrm{GHz}$, the loop is simulated for different widths ranging from $0.4 \mathrm{~mm}$ to $0.8 \mathrm{~mm}$. Loop radius is chosen as 13.2 $\mathrm{mm}$ only after multiple simulations. $\Omega$ ranges from 12.05 to 13.44 for the specified widths and radius of $13.2 \mathrm{~mm}$. Thus the loop remains a thin loop antenna for all the widths considered and resonates at more than one frequency [7]. Variation in resistance and reactance w.r.t. to loop width is shown in Figure 3. Simulated results for printed loop are well in accordance with the theoretical results of wire antenna. Loop with the radius of $13.2 \mathrm{~mm}$ and width of $4 \mathrm{~mm}$ is also simulated to show the characteristics of the thick loop antenna. $\Omega$ calculated is 8.8 and so the loop falls into the category of the thick loop. It can be observed in figure 3 that the resistance of the loop is uniform and is near to $60 \Omega$. Similarly, antenna reactance is capacitive and is nearly $-100 \Omega$ for a larger band.

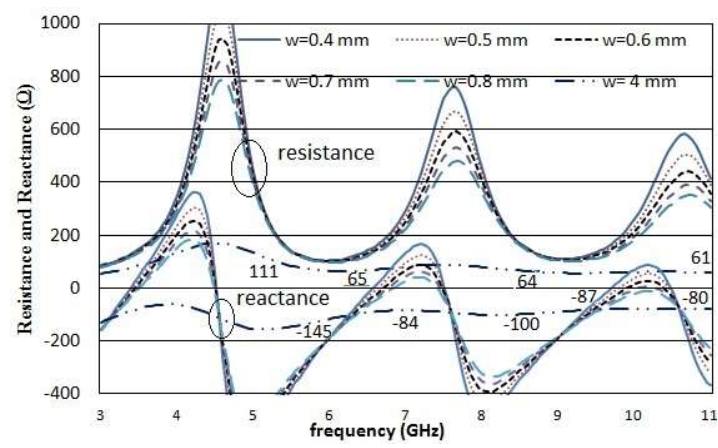

Figure 3: The Simulated Result of Frequency V/S Resistance for the Printed Loop Antenna. 
So far it is observed that for a loop antenna under the category of the large loop as the width increases resistance and reactance of the loop decreases, figure 3. This characteristic of the loop can be used to control the bandwidth of the antenna. To verify this property, the loop is also simulated for reflection coefficient for different widths ranging from $0.4 \mathrm{~mm}$ to $0.8 \mathrm{~mm}$. The simulated result is shown in Figure 4 and the result is

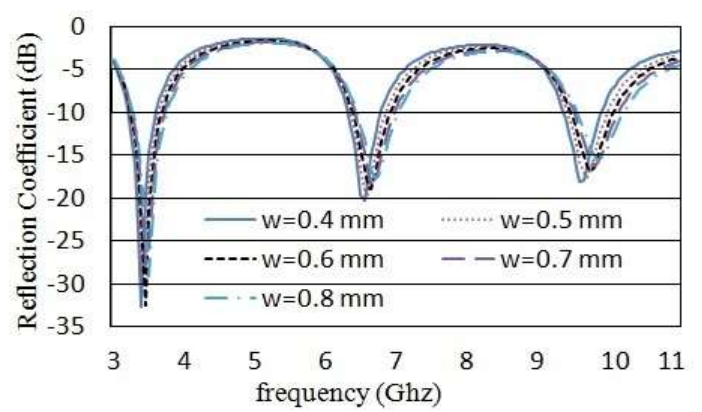

Figure 4: $\mathrm{S}_{11} \mathrm{~V} / \mathrm{S}$ Frequency of Printed Loop Antenna for Various Widths.

Table 1: Loop Antenna Showing Start and End Frequency.

\begin{tabular}{|c|c|c|c|}
\hline $\begin{array}{c}\text { Width of } \\
\text { loop(mm) }\end{array}$ & $\begin{array}{c}\boldsymbol{f}_{\boldsymbol{l}}-\boldsymbol{f}_{\boldsymbol{2}} \mathbf{G H z} / \\
\mathbf{B W} \\
(\mathbf{M H z})\end{array}$ & $\begin{array}{c}\boldsymbol{f}_{\boldsymbol{l}}-\boldsymbol{f}_{\mathbf{2}} \mathbf{G H z} \\
/ \mathbf{B W}( \\
\mathbf{M H z})\end{array}$ & $\begin{array}{c}\boldsymbol{f}_{\boldsymbol{l}}-\boldsymbol{f}_{2} \mathbf{G H z} / \\
\mathbf{B W}(\mathbf{M H z})\end{array}$ \\
\hline 0.4 & $\begin{array}{c}3.23-3.60 \\
(370)\end{array}$ & $\begin{array}{c}6.31-6.79 \\
(480)\end{array}$ & $\begin{array}{c}9.4-9.9 \\
(500)\end{array}$ \\
\hline 0.5 & $\begin{array}{c}3.22-3.63 \\
(410)\end{array}$ & $\begin{array}{c}6.33-6.85 \\
(520)\end{array}$ & $\begin{array}{c}9.42-9.98 \\
(560)\end{array}$ \\
\hline 0.6 & $\begin{array}{c}3.26-3.71 \\
(450)\end{array}$ & $\begin{array}{c}6.41-6.96 \\
(550)\end{array}$ & $\begin{array}{c}9.46-10.1 \\
(600)\end{array}$ \\
\hline 0.7 & $3.3-3.77$ & $6.4-6.9$ & $9.5-10.148$ \\
& $(450)$ & $(550)$ & $(638)$ \\
\hline 0.8 & $3.27-3.74$ & $6.44-7.03$ & $9.56-10.2$ \\
& $(470)$ & $(590)$ & $(650)$ \\
\hline
\end{tabular}

f1-lower cut off, f2-upper cut off in $\mathrm{GHz}$ tabulated in table 1. It confirms that there is an increase in the $-10 \mathrm{~dB}$ bandwidth of the loop antenna for an increase in antenna width.

Reference impedance of $125 \Omega$ is used to find $-10 \mathrm{~dB}$ bandwidth. Figure1 shows that each application band in UWB is of $528 \mathrm{MHz}$ wide. Our aim is to choose a loop satisfying this requirement of the wide band.

Table 2 (a) and 2 (b) tabulates the impact of the width of loop antenna on resonant frequency and resistance at the resonant frequency. The loop of width $0.6 \mathrm{~mm}$ produces a band of $550 \mathrm{MHz}$ and $600 \mathrm{MHz}$ and impedance ranges from $132 \Omega$ to $182.56 \Omega$, Table 1 and Table 2(a) respectively. $\Omega$ calculated using (1) for $\mathrm{w}=0.6 \mathrm{~mm}$ is 12.63 . Other widths of $0.7 \mathrm{~mm}$ and 0.8 $\mathrm{mm}$ also fulfil the requirement of the bandwidth of 528 $\mathrm{MHz}$ but the impedance is larger at the higher frequency, Table 1 and Table 2 (b) respectively. Larger impedance introduces difficulty in impedance matching. Therefore lower reference impedance is chosen which satisfies both the requirement of 528 $\mathrm{MHz}$ bandwidth and impedance matching. Therefore result in figure 4 is produced w.r.t. reference impedance of $125 \Omega$. Further reduction in reference impedance of $125 \Omega$ does not fulfil the requirement of the minimum bandwidth of $528 \mathrm{MHz}$. Other widths of $0.4 \mathrm{~mm}$ and $0.5 \mathrm{~mm}$ give smaller band than $528 \mathrm{MHz}$, Table1, except $560 \mathrm{MHz}$ bandwidth for $0.5 \mathrm{~mm}$ width. Therefore only single band is available and cannot fulfil the requirement of multiband antenna.

These comparisons show that loop with the width of $0.6 \mathrm{~mm}$ can be a good candidate for the UWB multiband applications. Band-7 ranges from 6.336 $\mathrm{GHz}$ to $6.864 \mathrm{GHz}$ and is not covered by the loop of width $0.6 \mathrm{~mm}$ as the start frequency at second resonance is $6.41 \mathrm{GHz}$, table1. The upper band for this width is from $9.46 \mathrm{GHz}$ to $10.1 \mathrm{GHz}$ and covers Band13. There is a third band available from $3.26 \mathrm{GHz}$ to $3.71 \mathrm{GHz}$ with a bandwidth of $450 \mathrm{MHz}$. But this band is not suitable for the application. Increase in the loop

Table 2(a): Resonant Frequency and Resistance of Loop for Various Widths.

\begin{tabular}{|c|c|c|c|c|c|c|}
\hline Width & \multicolumn{2}{|c|}{$0.4 \mathrm{~mm}$} & \multicolumn{2}{c|}{$0.5 \mathrm{~mm}$} & \multicolumn{2}{c|}{$0.6 \mathrm{~mm}$} \\
\hline $\begin{array}{c}\text { SR. } \\
\text { No. }\end{array}$ & $\begin{array}{c}\text { Resonant } \\
\text { Frequency }(\mathrm{GHz})\end{array}$ & $\begin{array}{c}\text { Resistance } \\
(\Omega)\end{array}$ & $\begin{array}{c}\text { Resonant } \\
\text { Frequency }(\mathrm{GHz})\end{array}$ & $\begin{array}{c}\text { Resistance } \\
(\Omega)\end{array}$ & $\begin{array}{c}\text { Resonant } \\
\text { Frequency }(\mathrm{GHz})\end{array}$ & $\begin{array}{c}\text { Resistance } \\
(\Omega)\end{array}$ \\
\hline 1 & 3.39 & 125.36 & 3.5 & 128.5 & 3.47 & 132 \\
\hline 2 & 6.57 & 155 & 6.62 & 159.2 & 6.69 & 164 \\
\hline 3 & 9.7 & 167.7 & 9.78 & 176.7 & 9.87 & 182.56 \\
\hline
\end{tabular}

Table 2(b): Resonant Frequency and Resistance of Loop for Various Widths.

\begin{tabular}{|c|c|c|c|c|}
\hline Width & \multicolumn{2}{|c|}{$0.7 \mathrm{~mm}$} & \multicolumn{2}{c|}{$0.8 \mathrm{~mm}$} \\
\hline $\begin{array}{c}\text { SR. } \\
\text { No. }\end{array}$ & $\begin{array}{c}\text { Resonant } \\
\text { Frequency }(\mathrm{GHz})\end{array}$ & Resistance $(\Omega)$ & $\begin{array}{c}\text { Resonant } \\
\text { Frequency }(\mathrm{GHz})\end{array}$ & Resistance $(\Omega)$ \\
\hline 1 & 3.477 & 132.8 & 3.49 & 133.5 \\
\hline 2 & 6.76 & 170 & 6.83 & 176.11 \\
\hline 3 & 10.04 & 209.4 & ----- & ----- \\
\hline
\end{tabular}


Helix Vol. 8(4): 3481- 3490

Table 3 Analysis of Effect of Feed Line on Bandwidth

\begin{tabular}{|c|c|c|c|c|c|c|c|c|c|}
\hline Folded & \multicolumn{3}{|c|}{ Case-1 (2.6mm) } & \multicolumn{3}{|c|}{ Case-2 (3.1 mm) } & \multicolumn{3}{|c|}{ Case-3 (3.6 mm) } \\
\hline $\begin{array}{c}\text { Length } \\
\text { of } \\
\text { main } \\
\text { feed } \\
\text { (mm) } \downarrow\end{array}$ & $\begin{array}{c}f_{1-f_{2}} \\
\mathrm{GHz} / \\
\mathrm{BW} \\
(\mathrm{MHz})\end{array}$ & $\begin{array}{c}f_{1}-f_{2} \\
\mathrm{GHz} / \\
\mathrm{BW} \\
(\mathrm{MHz})\end{array}$ & $\begin{array}{c}f_{1}-f_{2} \mathrm{GHz} / \\
\mathrm{BW} \\
(\mathrm{MHz})\end{array}$ & $\begin{array}{c}f_{1-f_{2}} \\
\mathrm{GHz} / \\
\mathrm{BW} \\
(\mathrm{MHz})\end{array}$ & $\begin{array}{c}f_{1-f_{2}} \\
\mathrm{GHz} / \\
\mathrm{BW} \\
(\mathrm{MHz})\end{array}$ & $\begin{array}{c}f_{1-f_{2}} \\
\mathrm{GHz} / \\
\mathrm{BW} \\
(\mathrm{MHz})\end{array}$ & $\begin{array}{c}f_{1}-f_{2} \\
\mathrm{GHz} / \\
\mathrm{BW} \\
(\mathrm{MHz})\end{array}$ & $\begin{array}{c}f_{1}-f_{2} \mathrm{GHz} \\
/ \mathrm{BW} \\
(\mathrm{MHz})\end{array}$ & $\begin{array}{c}f_{1}-f_{2} \\
\mathrm{GHz} / \\
\mathrm{BW} \\
(\mathrm{MHz})\end{array}$ \\
\hline 3.625 & $\begin{array}{c}3.21- \\
3.64 \\
(430)\end{array}$ & $\begin{array}{c}6.34- \\
6.95 \\
(610)\end{array}$ & $\begin{array}{c}9.35- \\
10.135 \\
(785)\end{array}$ & --- & ---- & ------- & $\begin{array}{l}------ \\
\end{array}$ & $-\cdots$ & ------ \\
\hline 4.125 & $\begin{array}{c}3.23- \\
3.66 \\
(430)\end{array}$ & $\begin{array}{c}6.32- \\
6.95 \\
(630)\end{array}$ & $\begin{array}{c}9.33- \\
10.37 \\
(1040)\end{array}$ & $\begin{array}{c}3.21- \\
3.65 \\
(440)\end{array}$ & $\begin{array}{c}6.29- \\
6.91 \\
(620)\end{array}$ & $\begin{array}{c}9.25- \\
10.29 \\
(1040)\end{array}$ & $\begin{array}{c}3.21- \\
3.64 \\
(430)\end{array}$ & $\begin{array}{c}6.26-6.89 \\
(630)\end{array}$ & $\begin{array}{c}9.19- \\
10.21 \\
(1020)\end{array}$ \\
\hline 4.625 & $\begin{array}{l}3.22- \\
3.65 \\
(430)\end{array}$ & $\begin{array}{c}6.3-6.95 \\
(650)\end{array}$ & $\begin{array}{c}9.35- \\
10.52 \\
(1172)\end{array}$ & $\begin{array}{c}3.21- \\
3.64 \\
(430)\end{array}$ & $\begin{array}{c}6.27- \\
6.92 \\
(650)\end{array}$ & $\begin{array}{c}9.27- \\
10.44 \\
(1169)\end{array}$ & $\begin{array}{c}3.21- \\
3.63 \\
(420)\end{array}$ & $\begin{array}{c}6.26-6.9 \\
(650)\end{array}$ & $\begin{array}{c}9.19- \\
10.33 \\
(1140)\end{array}$ \\
\hline 5.125 & $\begin{array}{l}3.21- \\
3.64 \\
(430)\end{array}$ & $\begin{array}{c}6.29- \\
6.98 \\
(690)\end{array}$ & $\begin{array}{c}9.4-10.67) \\
(1270)\end{array}$ & $\begin{array}{l}3.20- \\
3.63 \\
(430)\end{array}$ & $\begin{array}{l}6.26- \\
6.95 \\
(688)\end{array}$ & $\begin{array}{l}9.31- \\
10.56 \\
(1250)\end{array}$ & $\begin{array}{c}3.2-3.62 \\
(420)\end{array}$ & $\begin{array}{c}6.24-6.97 \\
(670)\end{array}$ & $\begin{array}{l}9.27- \\
10.48 \\
(1230)\end{array}$ \\
\hline 5.625 & $\begin{array}{c}3.2-3.64 \\
(440)\end{array}$ & $\begin{array}{r}6.28-7 \\
(720)\end{array}$ & $\begin{array}{c}9.46-10.7 \\
(1240)\end{array}$ & $\begin{array}{c}3.19- \\
3.63 \\
(440)\end{array}$ & $\begin{array}{c}6.26- \\
6.97 \\
(720)\end{array}$ & $\begin{array}{c}9.38- \\
10.6 \\
(1220)\end{array}$ & $\begin{array}{c}3.2-3.62 \\
(420)\end{array}$ & $\begin{array}{c}6.24-6.95 \\
(710)\end{array}$ & $\begin{array}{c}9.31- \\
10.52 \\
(1210)\end{array}$ \\
\hline 6.125 & --------- & --------- & --------- & $\begin{array}{c}3.19- \\
3.62 \\
(430)\end{array}$ & $\begin{array}{c}6.26- \\
7.02 \\
(760)\end{array}$ & $\begin{array}{c}9.46- \\
10.58 \\
(1124)\end{array}$ & $\begin{array}{c}3.18- \\
3.61 \\
(430)\end{array}$ & $\begin{array}{c}6.24- \\
6.99(750 \\
)\end{array}$ & $\begin{array}{c}9.37- \\
10.5 \\
6(1190)\end{array}$ \\
\hline
\end{tabular}

$\mathrm{h}=0.25 \mathrm{~mm}, \mathrm{~s}=0.36 \mathrm{~mm},, f 1$-lower cut off, $f 2$-upper cut off in $\mathrm{GHz}$

radius reduces the resonant frequency therefore by increasing the radius of the loop; lower cut off frequency of the second band can be reduced to cover band-7. But this leads to shifting of other bands and also causes an increase in the size of the loop. In order to improve the antenna performance to cover the two bands with the same radius a new feed is proposed and is shown in Figure 5 (a).

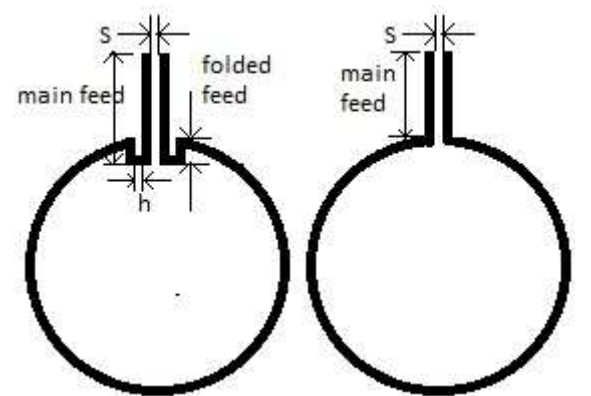

Figure 5: Loop Antenna with (a) Proposed Feed and (b) Conventional Feed.

New feed is the conventional CPS (coplanar stripline) only but with little modification in shape. Total length of the feed can be divided into i) folded length which is referred as folded feed and ii) main CPS feed referred as main feed, Figure 5(a). Table 3 summarizes the effect of main feed for three different lengths of folded feed. It can be seen that for all feed lengths, lower frequency band remains almost same and is less than $500 \mathrm{MHz}$. Therefore this band is not useful. It is also observed from Table 3 that the middle band increases with increase in main feed line for all the cases. Third band increases with increase in the main feed line until feed length of $5.125 \mathrm{~mm}$ and then decreases as the feed length increases. The middle band for all the cases is more than $528 \mathrm{MHz}$ and the third band is more than $1.056 \mathrm{GHz}$ for most of the cases; therefore a total of three bands can be covered. In order to keep the antenna size as compact as possible, the total length of the modified feed can be chosen from one of the three cases.

Table 3 shows that the middle band covers BAND-7 for all lengths from $4.125 \mathrm{~mm}$ to $6.125 \mathrm{~mm}$. BAND-13 has lower cut off frequency of $9.504 \mathrm{GHz}$ and upper cut off frequency at $10.032 \mathrm{GHz}$ whereas BAND-14 has the lower cut off frequency at $10.032 \mathrm{GHz}$ and upper cut off frequency at $10.56 \mathrm{GHz}$. These ranges of frequencies are well covered by loop when main feed line is $5.125 \mathrm{~mm}$. There is always a possibility that the measured result of implemented antenna deviates little from the simulated results. Therefore the feed lengths are chosen in such a way that the simulated bands are larger than the expected bands. As far as the size of the proposed loop is concerned, both the feed lengths (total length) with the main feed of $5.125 \mathrm{~mm}$ and $5.625 \mathrm{~mm}$ occupy the same area for the folded feed of $2.6 \mathrm{~mm}$ (case-1) and $3.1 \mathrm{~mm}$ (case-2) respectively. Since the folded feed for case- 2 is larger by $0.5 \mathrm{~mm}$ w.r.t. $2.6 \mathrm{~mm}$ folded feed of case-1, it penetrates more into the loop by $0.5 \mathrm{~mm}$, Figure 5 . Therefore the feed 
location of main feed from the loop is at the same distance $(2.525 \mathrm{~mm})$ for both the cases when main feed is $5.125 \mathrm{~mm}$ and $5.625 \mathrm{~mm}$. The proposed feed length is chosen from case- 1 of Table 3 and is of $5.125 \mathrm{~mm}$. For this particular case, the third band is wider than the third band of main feed of $5.625 \mathrm{~mm}$.

Other than this total physical length of the feed for case- 1 is smaller than the total physical length of feed (main feed + folded feed $+\mathrm{h}$ ) of case- 2 and is $(5.125$ $+0.25+2.6) 7.975 \mathrm{~mm}$. Thickness factor $\Omega$ of this loop is 12.63 . The first band is of $430 \mathrm{MHz}$ and is not useful since it is less than $528 \mathrm{MHz}$, Table. 3 .

In order to compare folded feeding technique with the conventional straight feed line, a printed loop of radius $13.2 \mathrm{~mm}$ with different lengths of straight feed line with a feed gap ' $\mathrm{S}$ ' of $0.36 \mathrm{~mm}$ is simulated, Figure 5. It can be observed that the entire feed remains outside the loop and thus the overall antenna occupies larger space than the proposed feed since the proposed feed has half of the length inside the loop and half outside it. Various bands generated by the loop with straight feed for reference impedance of $125 \Omega$ are tabulated in Table 4. It can be observed that when the feed length is $7.975 \mathrm{~mm}$ which is kept equal to the total feed length from proposed folded feed technique for optimum result, there are three $-10 \mathrm{~dB}$ bands available. The first band is of $420 \mathrm{MHz}$ wider and is not useful for the application. The second band is less than $1 \mathrm{GHz}$ so covers a single band BAND-8. The third band covers BAND-14. Hence a total of two bands are covered which is less than the number of bands covered by the folded feed technique with loop of same radius of $13.2 \mathrm{~mm}$. Larger length of the feed causes antenna to occupy larger area therefore to reduce the antenna area feed length is further reduced to $5.125 \mathrm{~mm}$ which is equal to the length of main feed from proposed feeding technique under the optimum result. For reduced feed length, first band remains almost similar to the earlier case, but the second band drops to $690 \mathrm{MHz}$ and covers BAND-7. The upper band is increased and covers BAND-13 and BAND14. Since antenna with feed $5.125 \mathrm{~mm}$ still occupies a larger area than the antenna with proposed feed, straight feed length is further reduced to $4.625 \mathrm{~mm}$. For this feed length, antenna covers BAND-7, BAND13 , and BAND-14. But the antenna area is still larger and it can also be observed in Table 4 that the lower and upper cut off frequencies are very much close to the recommended cut off frequencies. Hence any manufacturing limitation may shift the measured cut off frequencies lesser than the expected one. Further reduction in feed length leads to the reduction in the number of bands covered and only band BAND-7 and BAND-13 are covered. The last case of the length of $2.525 \mathrm{~mm}$ is included here purposely since for this case area occupied by the loop with straight feed and folded feed are same. But loop with the straight feed of 2.525 fails to cover any of the bands. It can also be observed from Table 4 that the pattern of variation of all the three bands is similar to the pattern of variation of all the bands of Table 3 for the increasing feeding

Table 4 Loop Antenna Showing Different Bands for the Straight Feed Line.

\begin{tabular}{|c|c|c|c|}
\hline $\begin{array}{c}\text { Length of } \\
\text { main feed } \\
(\mathrm{mm})\end{array}$ & $\begin{array}{c}f_{1}-f_{2} \mathrm{GHz} / \\
\mathrm{BW}(\mathrm{MHz})\end{array}$ & $\begin{array}{c}f_{1}-f_{2} \mathrm{GHz} / \\
\mathrm{BW}(\mathrm{MHz})\end{array}$ & $\begin{array}{c}f_{1-f_{2} \mathrm{GHz} /} \\
\mathrm{BW}(\mathrm{MHz})\end{array}$ \\
\hline 7.975 & $\begin{array}{c}3.18-3.6 \\
(420)\end{array}$ & $\begin{array}{c}6.49-7.44 \\
(950)\end{array}$ & $\begin{array}{c}9.81-10.6 \\
(790)\end{array}$ \\
\hline 5.125 & $\begin{array}{c}3.21-3.64 \\
(430)\end{array}$ & $\begin{array}{c}6.3-6.99 \\
(690)\end{array}$ & $\begin{array}{c}9.48-10.8 \\
(1320)\end{array}$ \\
\hline 4.625 & $\begin{array}{c}3.23-3.65 \\
(420)\end{array}$ & $\begin{array}{c}6.32-6.96 \\
(640)\end{array}$ & $\begin{array}{c}9.42-10.58 \\
(1160)\end{array}$ \\
\hline 4.125 & $3.23-$ & $6.33-6.96$ & $9.4-10.44$ \\
& $3.66(430)$ & $(630)$ & $(1040)$ \\
\hline 2.525 & $3.26-3.7$ & $6.4-6.96$ & $9.48-10.23$ \\
& $(440)$ & $(560)$ & $(750)$ \\
\hline
\end{tabular}

f1-lower cut off, f2-upper cut off in $\mathrm{GHz}$.

length.

The first band remains almost constant w.r.t. any increase in the feed line, second bandwidth increases with length and the third one first increases then decreases with increase in length.

\section{Interfacing Loop with BALUN}

Loop antenna is a balanced antenna and must be fed with a balanced feed. Since connectors available to feed any antenna are unbalanced in nature, a BALUN (balanced to unbalanced) transformer is required. There are different BALUNs available to feed balanced antenna such as taper BALUN [10] and compact BALUN [11]. Since the length of tapered BALUN is dependent on the mismatch between the reference impedance and the load impedance i.e. antenna impedance, BALUN is very large in size. In order to have a compact size of the antenna, instead of taper BALUN compact BALUN is used here. The structure of the BALUN is shown in Figure 6 along with the proposed loop. It can be observed in Figure 6 that the BALUN comprises of three sections: microstrip line MS which is unbalanced in nature, coupled microstrip line, then coplanar stripline which is balanced in nature. The width of the microstrip line is $2.42 \mathrm{~mm}$ for $50 \Omega$. Length of the microstrip line is chosen to accommodate SMA connector and is $5 \mathrm{~mm}$. Length of the middle section is about one-fourth of the wavelength of the central frequency of $3.1 \mathrm{GHz}-10.7$ GHz. Length of the coupled microstrip line after multiple simulations is taken as $8 \mathrm{~mm}$ with a gap of $3.3 \mathrm{~mm}$ between them. Coplanar stripline is designed to have a characteristic impedance of $125 \Omega$. Length of the coplanar line is chosen to have smallest possible length while keeping loop antenna away from the ground plane. Length of the coplanar line is $10 \mathrm{~mm}$. The gap between the coplanar lines is $0.2 \mathrm{~mm}$. The smaller length of CPS brings antenna closer to the ground plane and the antenna loses its desired characteristics. Loop antenna is connected at the port 
(2) of the printed BALUN transformer. Figure 7 shows the bandwidth of the BALUN when the impedance is $50 \Omega$ at the port (1) and $125 \Omega$ at the port (2). It can be observed in Figure 7 that the BALUN covers a band from $2.66 \mathrm{GHz}$ to $10.2 \mathrm{GHz}$.

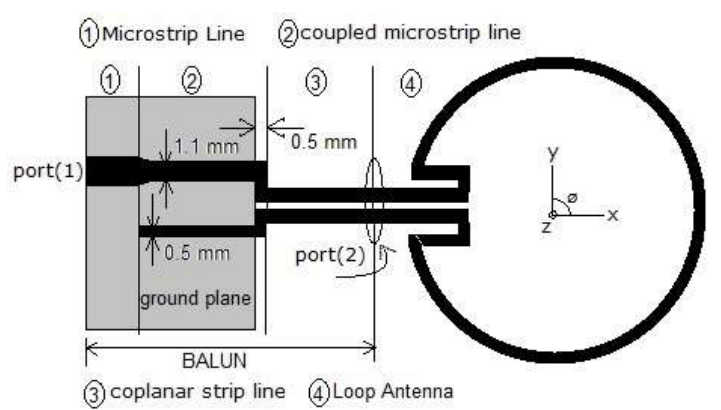

Figure 6: Compact BALUN Transformer Interfaced With the Loop at Port 2.

It also includes the simulated result of the reflection coefficient of the loop connected with BALUN transformer and loop without BALUN transformer. It can be observed that the loop antenna without BALUN produces three bands as discussed earlier but when it is connected with BALUN it produces 4 different -10 $\mathrm{dB}$ bands and covers seven different bands. The first band extends from $1.7 \mathrm{GHz}$ to $1.85 \mathrm{GHz}$ to cover GSM, the second is from $3.03 \mathrm{GHz}$ to $4.34 \mathrm{GHz}$ and covers BAND-1 and BAND-2. The third band ranges from $6.17 \mathrm{GHz}$ to $7.02 \mathrm{GHz}$ and covers BAND-7, the fourth ranges from $8.89 \mathrm{GHz}$ to $11 \mathrm{GHz}$ and it covers BAND-12, BAND-13, and BAND-14. When the loop is interfaced with BALUN three additional bands are generated. These bands are centred at $1.8 \mathrm{GHz}, 3.9$ $\mathrm{GHz}$ and $9.2 \mathrm{GHz}$. These bands are not present when the loop is not interconnected with BALUN. Possible reasons for the presence of these bands are discussed in next section.

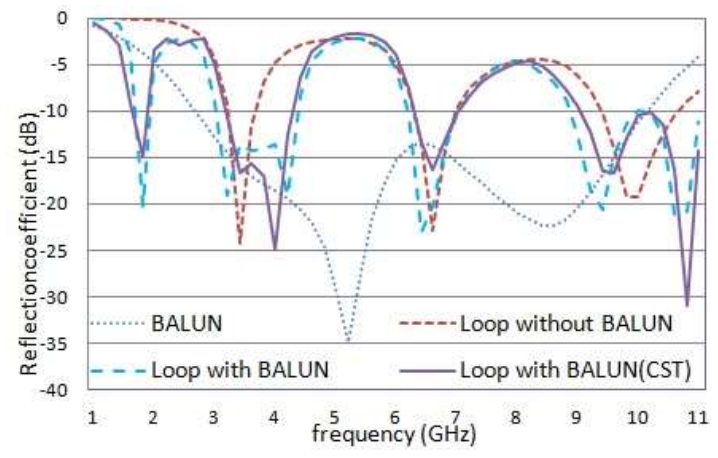

Figure7: $\mathrm{S}_{11}$ v/s Frequency Response of Loop, Loop Interfaced with BALUN along with BALUN response.

\section{Measurement of Loop with BALUN}

To check the validity of the proposed method loop is manufactured on Duroid 5880 and is tested using
Agilent Technologies: N9916A VNA. The measured result is reproduced along with the simulated one in figure 9. Figure 8 shows the photograph of the manufactured antenna.

It can be observed in Figure 9 that four distinct $-10 \mathrm{~dB}$ bands are available. the first one is available from 1.7 $\mathrm{GHz}$ to $1.85 \mathrm{GHz}$, the second from $3.094 \mathrm{GHz}$ to 4.44 $\mathrm{GHz}$, the third is available from $6.11 \mathrm{GHz}$ to $7 \mathrm{GHz}$ and the final is available from $8.85 \mathrm{GHz}$ to $10.5 \mathrm{GHz}$.

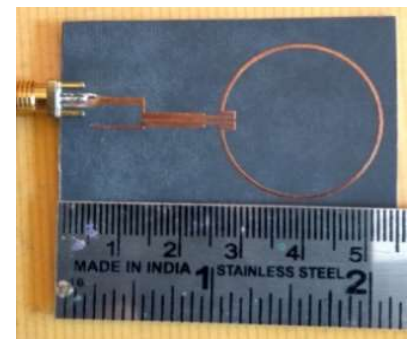

Figure 8: Photograph of the Manufactured Proposed Loop Antenna.

The measured and the simulated results are in close agreement. Loop antenna, when added to the BALUN, gives additional bands. In order to find out the possible reasons for the presence of these additional bands, current distribution along the loop with BALUN and wherever required loop without BALUN is analyzed and compared. The simulated result of current distribution along the loop is reproduced.

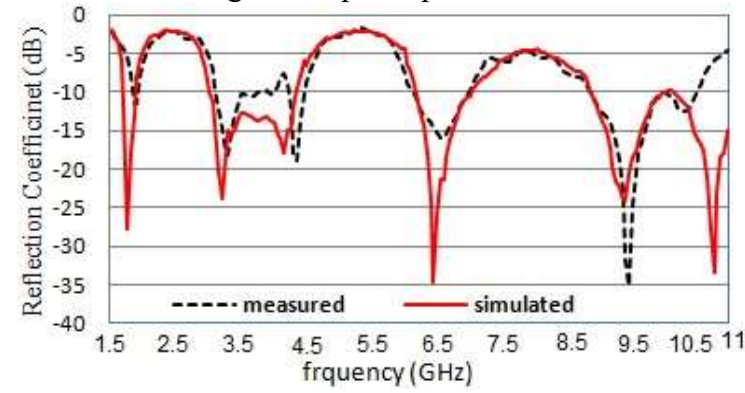

Figure 9: Measured and Simulated Result of the Proposed Loop Antenna.

Current distribution is presented in two different ways: a) distribution of current along circular loop with feed points 1,2 . b) same current distribution is reproduced along a straight line whose length equals to the length of the loop when it is open and made straight.

First band available is at $1.8 \mathrm{GHz}$ when the loop is interconnected with BALUN. Figure 10 (a) shows the current distribution in the loop when it is not interfaced with BALUN. A varying dotted line represents a varying magnitude of current and solid line with the arrow represents the direction of the current.

Segment "a" and "b" contain current distribution in the same direction. Segment "a" acts as simple dipole of very small length w.r.t. free space wavelength of $166.67 \mathrm{~mm}$ at $1.8 \mathrm{GHz}$. Segment "a" is excited with source and segment "b" acts like a passive reflector as 
it is not directly connected with the source. Length of this reflector is almost of length $\lambda / 2$ due to half-length current distribution as shown in Figure 10(a). This arrangement leads to radiation towards feed only i.e. in $-x$ direction. Distribution of current shows that the current is very small at feed point 1,2 . This small current leads to the poor match with the source and there is no band available when the loop in not connected with BALUN transformer.

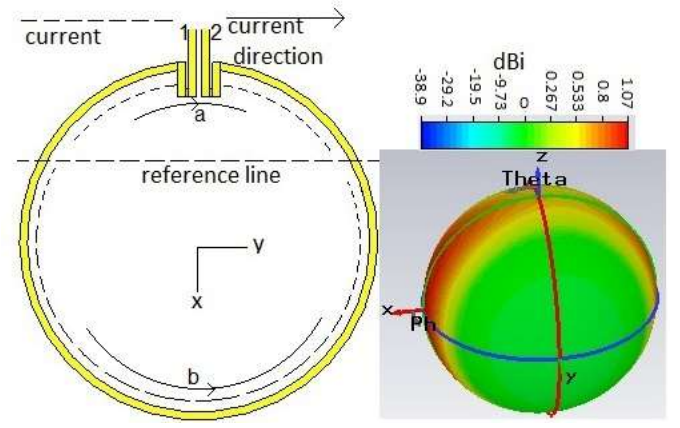

(a)

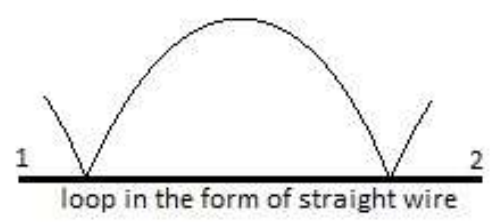

(b)

Figure10. (a) Simulated Current Distribution along Loop. (b) Radiation Pattern at $1.8 \mathrm{GHz}$ without BALUN.

Free space wavelength at $1.8 \mathrm{GHz}$ is $166.67 \mathrm{~mm}$. When the loop is interfaced with BALUN, overall length of the loop increases by BALUN length. BALUN length is $18.5 \mathrm{~mm}$ and since it is balanced in nature, current travels from MS line into one arm of the BALUN then into loop and from the loop it goes

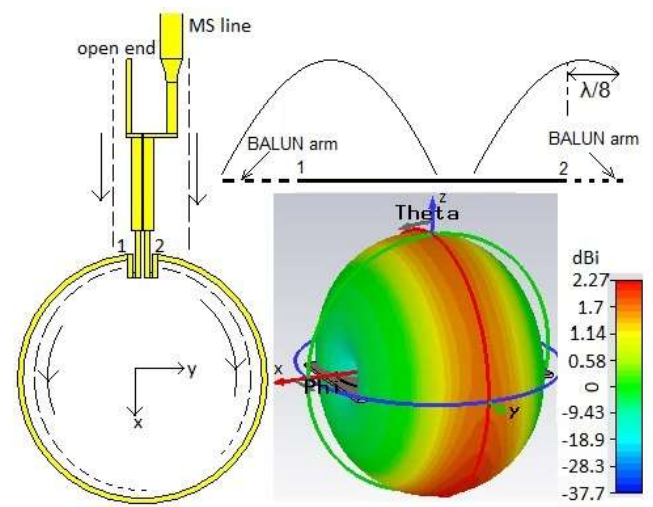

Figure11. Radiation Pattern and Current Distribution Along Loop at $1.8 \mathrm{GHz}$ with BALUN.

into the second arm of the BALUN. Therefore current can see twice of $18.5 \mathrm{~mm}$ length. Thus overall length of this entire structure becomes $37 \mathrm{~mm}+95.95 \mathrm{~mm}$
$($ loop length with folded feed $)=132.95 \mathrm{~mm}$, figure 11 . This length is almost equal to one wavelength at 1.8 $\mathrm{GHz}$ if effective dielectric constant of Duroid is taken into consideration. It is well known that loop with a circumference equal to one wavelength resonates at this wavelength and produces a band.

Alternately it can also be explained w.r.t. current distribution. It can be observed that the current at point 2 is larger than the earlier case of the loop without BALUN, Figure 10. BALUN length is $18.5 \mathrm{~mm}$ and is nearly $\lambda / 8$ at $1.8 \mathrm{GHz}$. BALUN arm connected to point 2 shifts the phase of the current by $45^{\circ}$. Therefore the magnitude of the current at point 2 and at MS feed is equal and large enough to establish matched condition. Other than this shift in current distribution shifts the orientation of the radiation pattern by $90^{\circ}$. Current distribution confined to loop is similar to simple dipole but of curved shape, therefore, the radiation is omnidirectional and is aligned along the $y$-axis, figure 11 .

In the earlier case, the loop circumference was nearly half of the wavelength at $1.8 \mathrm{GHz}$. Free space wavelength at $3.4 \mathrm{GHz}$ is almost equal to the circumference of the loop of $83 \mathrm{~mm}$. Distribution of current along the loop is equal to one wavelength, Figure 12 (a). Current at point 1,2 is weak and the inclusion of the BALUN at feed point 1, 2 improves the current distribution at MS feed. Current distribution around the reference line can be viewed

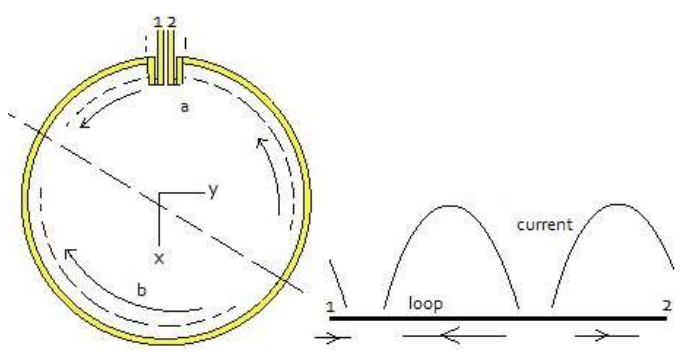

(a)

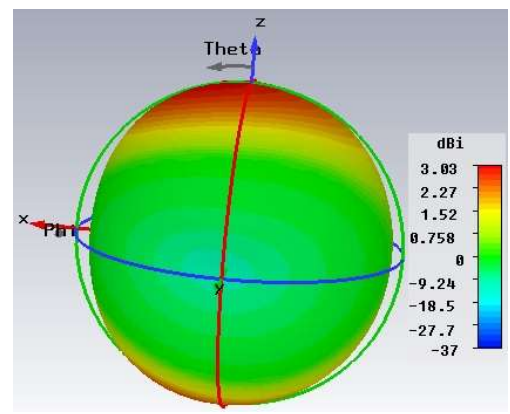

(b)

Figure12. (a) Simulated Current Distribution along the Loop. (b) Radiation Pattern at $3.4 \mathrm{GHz}$ with BALUN.

as if a folded dipole is formed. This leads to an omnidirectional pattern with improved gain, Figure 12 (b). The loop without BALUN does not produce any 
band at $3.96 \mathrm{GHz}$. Free space wavelength at $3.96 \mathrm{GHz}$ is $76 \mathrm{~mm}$ and loop circumference is $83 \mathrm{~mm}$, therefore, the loop is larger than the wavelength and current distribution is more than two half wavelengths as shown in Figure 13 (a). Length $\lambda / 4$ is $19 \mathrm{~mm}$ and this length is close to the length of the BALUN. This quarter length shifts the phase of the low current available at point 2 by $90^{\circ}$ to match the antenna with MS line. Current distribution along the loop can be divided in two parts "a-b" and part "c". Current distribution in part "a-b" is in the same direction but asymmetric w.r.t. feed at point 1,2 . When entire current distribution is viewed w.r.t. reference line it appears similar to the current distribution in a folded dipole. Radiation should be along $\pm \mathrm{z}$ axis. But unequal current distribution in "a - b" segments of loop deviates the radiation away from $\pm \mathrm{z}$-axis, Figure 13 (b). It is also observed in Figure 13 (b) that there is radiation in $(\mathrm{x},-\mathrm{y})$ direction. This is due to the asymmetric distribution of current in part "a - b". Part "b" is larger than "a" and contains larger current so the radiation is tilted more towards part " $b$ ". This gives radiation along $\pm \mathrm{z}$-axis and also in $(\mathrm{x},-\mathrm{y})$ direction.

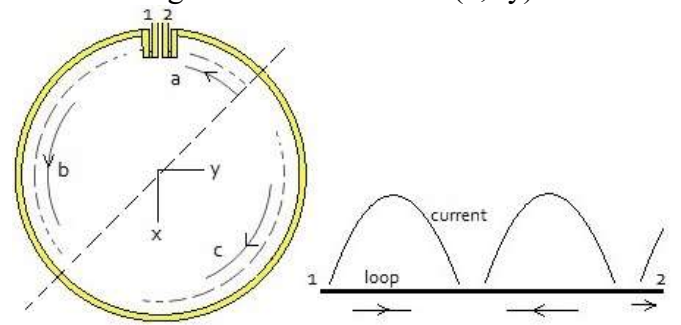

(a)

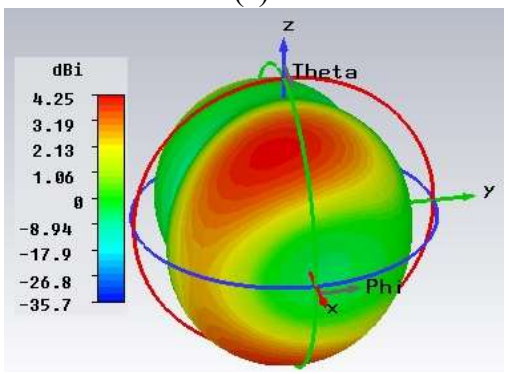

(b)

Figure13. (a) Simulated Current Distribution along the Loop. (b) Radiation Pattern at $3.96 \mathrm{GHz}$ with BALUN.

Free space wavelength at $6.6 \mathrm{GHz}$ is $45.45 \mathrm{~mm}$. The circumference of the loop without the folded feed is 83 $\mathrm{mm}$. Therefore it can be observed that there are more than three half cycles of current distribution along the loop. Radiation pattern can be explained w.r.t. the reference line passing through the centre of the loop. Part "a" and "b" can be viewed as folded dipole and similarly "d" and "c". These dipoles are formed along the reference line, Figure 14 (a). This current distribution is similar to the earlier case of $3.96 \mathrm{GHz}$ except for one more current component along the loop. The reference line is shifted in clockwise direction w.r.t. to the earlier current distribution. This shift in current

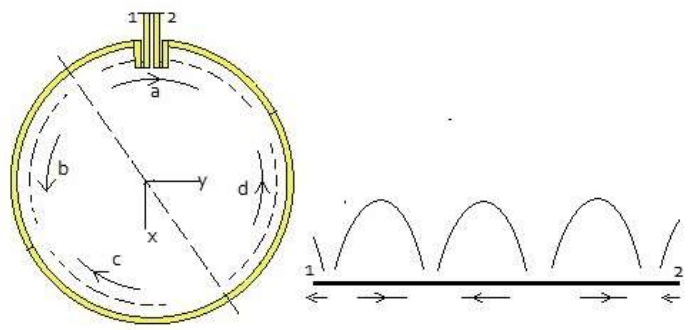

(a)

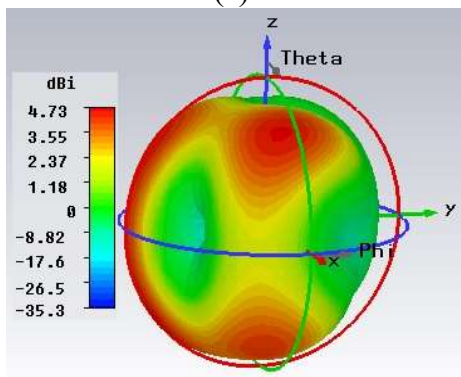

(b)

Figure14. (a) Simulated Current Distribution along the Loop. (b) Radiation Pattern at $6.6 \mathrm{GHz}$ with BALUN.

distribution shifts the pattern in the clockwise direction. It is well known that the radiation along the axis of the dipole is zero and this can be observed in the radiation pattern of the loop. Similarly, radiation between part " $b$ " and "c" and between "a" and " $d$ " is

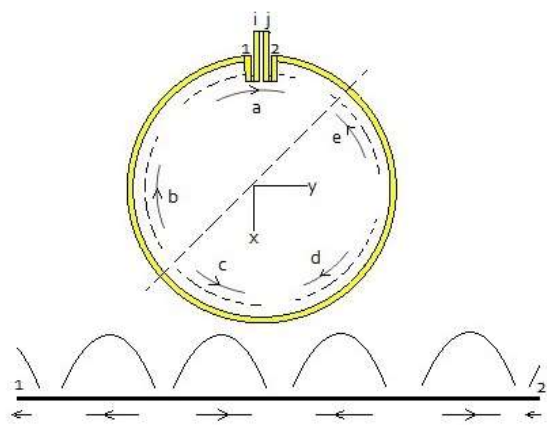

(a)

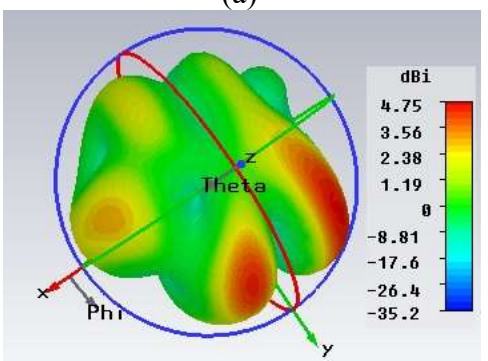

(b)

Figure15. a) Simulated Current Distribution along the Loop. (b) Radiation Pattern at 9.2 GHz with BALUN. 
absent as there is no current between part "b" and "c" and between "a" and "d", Figure 14 (b).

The band at $9.2 \mathrm{GHz}$ is available only if the loop is connected to the BALUN. Free space wavelength at this frequency is $32.6 \mathrm{~mm}$. Loop circumference is 83 $\mathrm{mm}$ so able to accommodate more than two full wavelength current distributions and is clearly evident in the current distribution, Figure 15 (a).

Current distribution along the loop is viewed around the reference line as shown in Figure 15 (a). Currents in part "a"-"b" and "c"-"e" can be viewed as array of folded dipole and in phase. This arrangement of currents should give radiation along the $\pm \mathrm{Z}$ axis but the involvement of " $\mathrm{d}$ " component alters the pattern and the radiation is available in $(-\mathrm{x}, \mathrm{y})$ and $(\mathrm{x}, \mathrm{y})$ directions as shown in radiation pattern, Figure 15 (b). Nulls exist along the reference axis and between "a" -"b", "c"-"d" and "d"-"e".

It can be observed that the current at point 2 on the loop is very small. Folded feed whose length is 7.975 $\mathrm{mm}$ is approximately $\lambda / 4$ in length and it transforms the current to maximum value at point $\mathrm{j}$ in Figure 15 (a). Length of the BALUN is $18.5 \mathrm{~mm}$ and is close to $\lambda / 2$ in length at $9.2 \mathrm{GHz}$. It is well known that a load seen through a line of length $\lambda / 2$ remains unchanged. Therefore a current maximum available at point $\mathrm{j}$ is also available to MS line feeding the BALUN and hence matching is achieved and an additional band is available at $9.2 \mathrm{GHz}$.

When the frequency is further increased to $9.7 \mathrm{GHz}$ free space wavelength drops to $30.9 \mathrm{~mm}$. The loop of circumference $83 \mathrm{~mm}$ can accommodate more than 2.5 wavelength current distributions and is shown in Figure 16 (a). Current distribution is similar to that of the earlier case of $9.2 \mathrm{GHz}$ except for one more component of current due to increase in the frequency. Now there are total three pairs of half wavelength current distribution available. Current pairs "a"-" $\mathrm{f}$ " and "c"-" $\mathrm{d}$ " radiates along $\pm \mathrm{z}$ axis as they are in phase but the additional pair "b"-"e" is opposite in phase and alters the pattern. The presence of current pair "b"-"e" improves the radiation in $(\mathrm{x}, \mathrm{y})$ direction compared to the earlier case of $9.2 \mathrm{GHz}$. The nulls are available along reference axis and between the two consecutive current components.

Current distribution at $10.3 \mathrm{GHz}$ is similar to that of current distribution at $9.7 \mathrm{GHz}$, Figure 17 (a). The only difference is that the current distribution is shifted in clock-wise direction w.r.t. the earlier current distribution. The impact of this rotation in current distribution is clearly visible in the radiation pattern, Figure 17 (b). Current component "a" and "d" is in opposite direction as compared to the remaining current components. This pair is responsible for deviating the radiation from $\pm \mathrm{Z}$. Maximum radiation is available in $(\mathrm{x}, \mathrm{y})$ direction due to rotation of current components. Nulls are present along the reference axis and between all the consecutive current components.

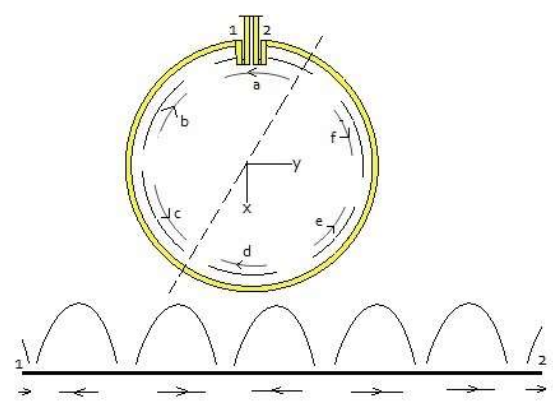

(a)

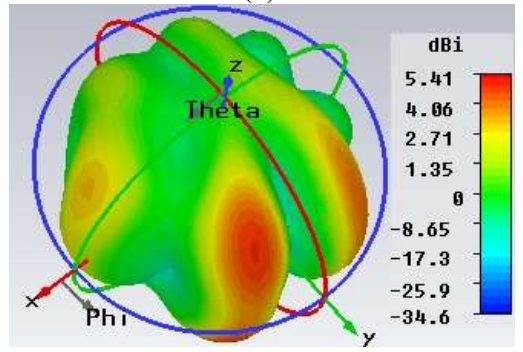

(b)

Figure16. a) Simulated Current Distribution along the Loop. (b) Radiation Pattern at 9.7 GHz with BALUN.
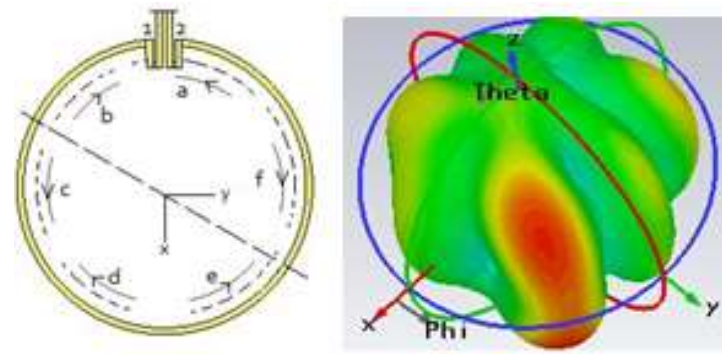

(a)

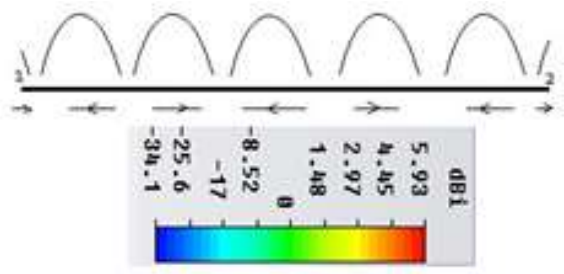

(b)

Figure17: (a) Radiation Pattern at $10.3 \mathrm{GHz}$ (b) Simulated Current Distribution along Loop with BALUN.

\section{Conclusion}

It is shown that multiple bands can be achieved using simple printed loop antenna without using the reconfigurable technique. A new folded feed is proposed to feed the balanced loop. This feed can be applied to any balanced antenna. The advantage of the feed is that it reduces onboard space. The proposed multi-band loop is capable to generate four distinct 
bands which cover six different bands from UWB group and one GSM band when interfaced with broadband printed BALUN transformer. The first band is available from $1.7 \mathrm{GHz}$ to $1.85 \mathrm{GHz}$ and covers upper GSM. The second band is from $3.09 \mathrm{GHz}$ to $4.44 \mathrm{GHz}$ and covers BAND-1 and BAND-2. The third band ranges from $6.11 \mathrm{GHz}$ to $7 \mathrm{GHz}$ and covers BAND-7, the fourth band ranges from $8.85 \mathrm{GHz}$ to $10.5 \mathrm{GHz}$ and it covers BAND-12, BAND-13, and BAND-14.

It is also found that the antenna rejects IEEE 802.11 $\mathrm{Wi}-\mathrm{Fi} / \mathrm{WLAN}$ at $5.8 \mathrm{GHz}$. Complete analyses of the current distribution along the loop reveal that at higher frequencies antenna current does not remain uniform and the radiation pattern fluctuates. Therefore the proposed antenna cannot be used for all the six bands at a time but can be used only for three different bands at a time i.e. from $3 \mathrm{GHz}$ to $7 \mathrm{GHz}$ together and from $8.85 \mathrm{GHz}$ to $10.5 \mathrm{GHz}$ together as the second group. To improve the antenna performance to have constant radiation pattern, RIS (reactive impedance surface) or other metamaterials can be introduced along with the proposed loop antenna.

\section{Acknowledgement}

Authors would like to express their thanks to Dr. Rajiv Gupta of Terna College of Engineering, Navi Mumbai, Maharashtra, India to provide support for the measurement of antennas. Authors are also very much grateful to the ROGERS Corporation for providing Duroid substrate.

\section{References}

[1] C.W. Chiu and C.H. Chang, Multi Folded Loop Antenna For Smart Phones, Progress In Electromagnetics Research, PIER 102, 213-226, 2010.

[2] Hao Wang et.al. Small Size Re-configurable Loop Antenna for Mobile Phone Application, https://www.researchgate.net/publication/305523436.

[3] Chia-Mei Peng, I-Fong Chen, and Ji-Wei Yeh, Printed Broad Asymmetric Dual-Loop Antenna for WLAN/Wi MAX Applications, IEEE Antennas And Wireless Propagation Letters, VOL. 12, 2013.

[4] Kuiwen Xu et.al., Multi-mode and Wide Printed Loop Antenna Based on Degraded Split-Ring Resonators, Journal of Latex Class Files, Vol. 14, No. 8, August 2015.

[5] Jiangniu $\mathrm{Wu}$ et.al., A Printed Unidirectional Antenna With Improved Upper -Edge Selectivity Using a Parasitic Loop, IEEE Transactions On Antennas And Propagation, Vol. 63, No. 4, April 2015.

[6] Wang-Table Hsieh and Jean-Fu Kiang, Small Broad Antenna Composed of Dual-Meander Folded
Loop and Disk-Loaded Monopole, IEEE Transactions On Antennas And Propagation, Vol. 59, No. 5, May 2011.

[7] Quirino Balzano and Kezimierz Siwiak, The Near Field of Annular Antennas, IEEE Transaction on Vehicular Technology, Vol. VT-36, No.-4, November 1987.

[8] Constentine A. Balanis, Loop Antennas, in Antenna Theory: Analysis and Design, $3^{\text {rd }}$ ed, Hoboken, New Jersey, John Wiley \& Sons, 2010, pp 257.

[9] Rong-Lin et. al., Circular Polarized OpenLoop Antenna, IEEE Transactions On Antennas And Propagation, Vol. 51, No. 9, September 2003.

[10] Wen-Hua Tu, and Kai Chang,, Widemicrostrip-to-Coplanar Stripline/Slot line Transitions, IEEE Transactions On Microwave Theory And Techniques, Vol. 54, No. 3, March 2006.

[11] Teck Beng Lim and Lei Zhu, Compact Microstrip-to-CPS Transition for UWB Application, 2008 IEEE MTT-S International Microwave Workshop Series on Art of Miniaturizing RF and Microwave Passive Components. 